\title{
The Implementation Of Left Corner Parsing In Indonesian Language
}

\author{
Dewi Soyusiawaty, Andri Pranolo \\ \{dewi.soyusiawaty@tif.uad.ac.id ${ }^{1}$, andri.pranolo@tif.uad.ac.id $\left.{ }^{2}\right\}$ \\ Informatics Department, Universitas Ahmad Dahlan, Yogyakarta, Indonesia ${ }^{1,2}$
}

\begin{abstract}
Indonesian language is a national language spoken not only by Indonesian citizens but also foreign citizens when they are in Indonesia. The communication is carried out through a lot of media both written and orally. Computer based translator applications now not only rely on written input but also spoken one. Whereas, it's not sure whether the inputted sentence is grammatically correct or not. When the inputted sentence is incorrect, it will influence the result given by the translator application. One method to know whether the input is correct or not is by checking the sentence pattern. This research explains left corner parsing applied on sentence pattern tracking. Left corner parsing is a combination of top down and bottom up parsing by taking top down prediction and bottom up tracking. From the two tracking techniques, the sentence will be parsed to be token per token and then the grammar rule which is previously determined is searched. With the tracking and prediction, a parser to parse the sentence will be gotten, so the sentence pattern will be identified. This research discusses and makes an auxiliary tool which function is to identify the pattern of Indonesian language sentences. As a result, it can be identified whether the pattern of the inputted sentence is correct or not based on the stored grammar rule in the application.
\end{abstract}

Keywords: Parsing, Left Corner, Indonesian Language.

\section{Introduction}

\subsection{Problem}

Now days translator software can helps people to translate from one to another language in a relative short time for a relative huge number of words. However, the fact shows that translation result from the software is not yet reliable enough since most of them only translate based on the words from the source language. To produce a good translation in the target language, we can't rely on it because there are many factors influencing the quality of a translation such as the grammar structure of a language which is not always the same. The structure of the inputted sentence which is grammatically incorrect will affect the translation result [1].

As the Indonesian language instruction effort and pilot study to develop translator application applying parsing concept chosen to produce information whether inputted sentence pattern is grammatically correct or not, so an application to check the sentences can be developed. Parsing algorithm used is left corner parsing. This method is a combination of bottom up and top down parsing method. Generally this is bottom up parsing method, but a top down prediction is applied in this method [2]. 


\section{Context Free Grammar}

Context Free Grammar (CFG) is used to explain the syntax of a language. Grammar is a form of human's natural language used in the daily communication. Every grammar rule has a syntactic structure that can be described by a grammar.

The components of CFG:

1. A group of token namely terminal

2. A group of non-terminal

3. A group of production rules

4. First symbol

In the CFG it needs to understand the following terms related to grammar in order to differentiate one symbol to another.

1. The following symbols are terminal

a. Lowercase letter, in the first alphabet letters such as a, b, or c

b. Operator symbols such as @, \#, -, etc

c. Number $0,1,2$, etc

2. The following symbols are non-terminal

Capital letter, from alphabet, A, B and C

The first symbol

3. A lowercase letter of the end of alphabet such as $u, v, \ldots z$ represents a group of terminal

4. A lowercase Greek letter such as $\alpha, \beta, \mu$ as an example represents a group of grammar symbol

5. If no another statement, the left part of production is the first symbol [3].

CFG is a language rule consisting of two parts. It left side consists of one non-terminal symbol. By using this grammar rule, the analysis result from a sentence forms a tree structure. This kind of tree is called parse tree. The example of CFG rule as following:

1. sentence $\rightarrow \mathrm{np}, \mathrm{vp}$

2. $\mathrm{np} \rightarrow$ noun, det

3. np $\rightarrow$ noun

4. $\mathrm{vp} \rightarrow$ verb, $\mathrm{np}$

5. $v p \rightarrow v p, p p$

6. $\mathrm{pp} \rightarrow$ prep, $\mathrm{np}$

7. det $\rightarrow$ [itu]

8. noun $\rightarrow$ [anak]

9. noun $\rightarrow$ [anjing]

10. noun $\rightarrow$ [tongkat]

11. verb $\rightarrow$ [memukul]

12. prep $\rightarrow$ [dengan]

If the sentence on the CFG above is stated as a beginner symbol, the sentence 'anak itu memukul anjing dengan tongkat' will be analyzed by using grammar rules above by forming a beginner symbol (sentence) and then it will form a tree as following: 


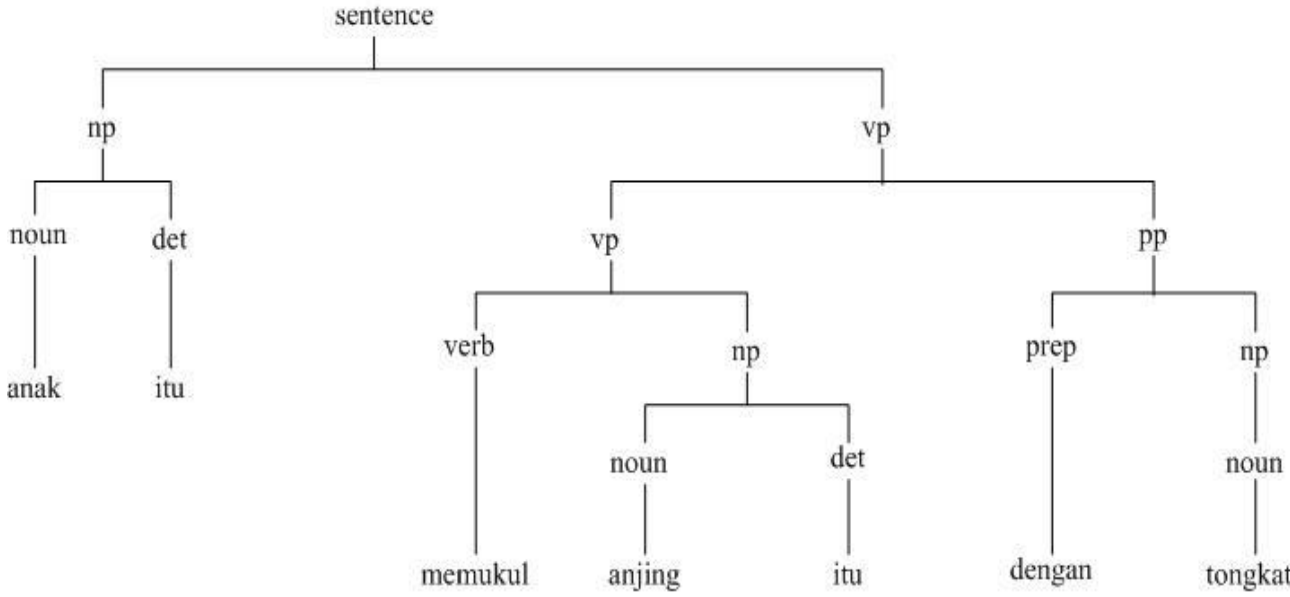

Fig. 1. Tree Structure

In the sentence structure analysis or parsing, there are two main methods which are top down and bottom up parsing method. In the top down parsing, the tree structure formation is done from top to down. Therefore, if the grammar rule uses CFG rule, the tree structure formation is done by forming non-terminal symbol on the left side of CFG rule. It is then continuously transformed to the right side until the terminal symbol is found. In the bottom up parsing, the transformation happens in opposite; the right side of CFG rule is transformed to the left side. Therefore, in this bottom up parsing method, the tree structure formation starts from its terminal symbol [4].

\section{Kaidah : $\mathrm{x}$

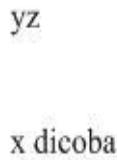

(a)

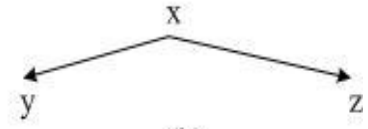

(b)

Fig. 2. Top Down Parsing
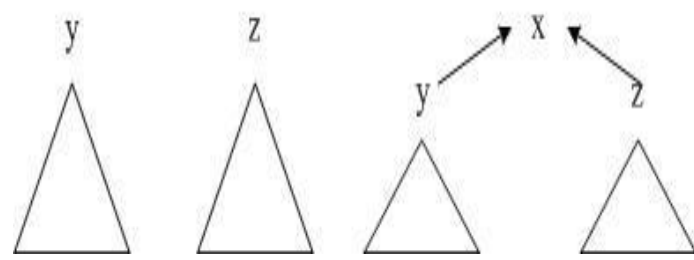

Fig. 3. Bottom Up Parsing

The writing of grammar in the natural language with CFG usually consists of ambiguity. For instance the writing of CFG rules on the (d) and (e) above. To analyze all possibilities written in the CFG rules, a back tracking mechanism is necessary. By using this mechanism, if in the analysis process some possibilities are found, one of them is chosen to be analyzed further until the analysis can't be continued further. At the moment, back tracking occurs and 
other possibilities are tracked. Therefore, by the existence of back tracking it is possible to form more than one analysis or parse tree [5].

\subsection{Left Corner Parsing}

This method is a combination between bottom up and top down parsing. Generally this is bottom up parsing method, but a top down prediction is applied in this method.

As in the bottom up parsing, an analysis starts with the first word input from the sentence. The suitable CFG rule is then searched, but in this method, the right side of CFG rule does not need to completely match. If only the first part matches, so that rule is used. Then the rest words become the new searching target. In this method, the tree structure formation occurs one by one part. When the searching target which is a prediction is successful, so the new tree structure is formed consisting of successful trees. The following example in the figure 4 will explain it.

The searching area using this method is wider; it means that the tracking scope is also wider, so the possibility of the successful searching is bigger. As a result, the possibility of back tracking to occur is fewer. Even if it occurs, it's only in the closer area.

A more definite tracking can be done by giving information when prediction is done to form a certain phrase. As known that verb is an element to form vp, preposition is an element to form $\mathrm{pp}$ and $\mathrm{np}$, which is element to form bigger phrase such as sentence, etc. By giving clear elements to form a phrase, the possibility of phrase formation failure can be identified as early as possible, so the useless tracking can be limited [5].

\subsection{Indonesian Language Grammar}

The sentence constructor structure is physically the clause. The clause is a lingual unit consisting of minimal subject $(\mathrm{S})$ and predicate $(\mathrm{P})$. The other clause constructor elements are object (O), complement/pelengkap (Comp/Pel) and adverb/keterangan (Adv/K). The following Table 1 is the clause structure pattern in Indonesian language that is commonly used [6]. 

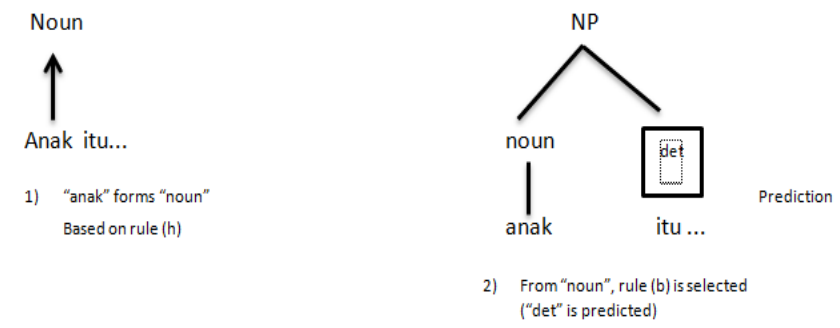

2) From "noun", rule (b) is selected
("det" is predicted)
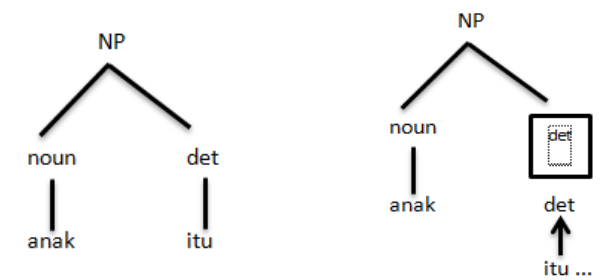

4) Prediction "det" is fulfilled

3) "itu" forms "det"
Based on rule (g)

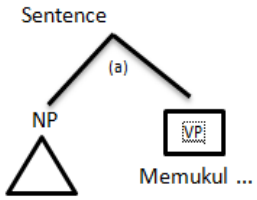

5) From "NP", rule (a) is selected (vp is predicted)

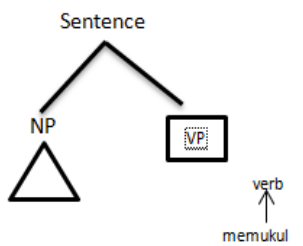

6) memukul forms "verb
based on rule (k)

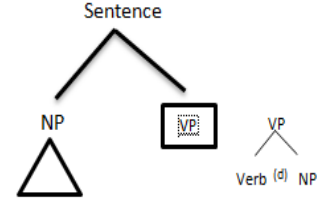

Sentence

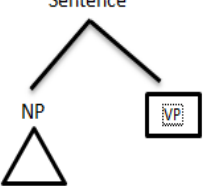

Anjing itu

7) based on "verb" rule (d)

is selected (NP is predicted)

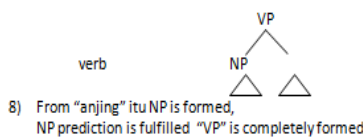

$\overbrace{\triangle \triangle_{\text {verb }}^{\text {Np }}}^{\text {Sentence }}$
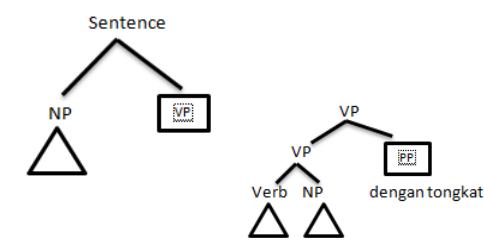

9) VP prediction is fulfilled

10) Based on "VP" rule (e)
is selected ( $P$ i is pred

Verb NP dengantongkat

Fig. 4. Left Corner Parsing 
Table 1. Clause Structure

\begin{tabular}{lll}
\hline No & Pattern Clause & \multicolumn{1}{c}{ Example of sentences } \\
\hline 1 & S-P & Dia belajar \\
2 & S-P-O & Adik makan roti \\
3 & S-P-Pel & Aku belajar menari \\
4 & S-P-O1-O2 & Kakek membelikan adik sepeda baru \\
5 & S-P-O-K & Ia menendang bola ke atas atap rumah \\
6 & S-P-Pel-K & Aku berenang gaya katak di Umbul Tirto kemarin \\
7 & S-P-O1-O2-K & Kakek membelikan adik sepeda baru kemarin \\
\hline
\end{tabular}

A phrase is a grammatical unit consisting of two or more words which do not cross the clause function. The following Table 2 shows the type of phrase, pattern and the example. From the clause pattern and the phrase type, the basic sentence pattern can be combined. It consists of the functions which are filled by the phrase that consists of the word categories. The sentence structure can be shown in the Table 4 with the following compositions [7] [6]:

Table 2. Clause Pattern

\begin{tabular}{|c|c|c|c|c|c|}
\hline \multirow{2}{*}{$\begin{array}{c}\text { No } \\
1\end{array}$} & \multicolumn{5}{|c|}{ Pattern } \\
\hline & \multirow{2}{*}{$\begin{array}{l}\mathrm{S} \\
\mathrm{N}\end{array}$} & $P$ & & & \\
\hline & & \multicolumn{4}{|l|}{$\mathrm{N}$} \\
\hline & & \multicolumn{4}{|l|}{ V } \\
\hline & & \multicolumn{4}{|l|}{ Bil } \\
\hline & & \multicolumn{4}{|c|}{ Ket } \\
\hline \multirow[t]{2}{*}{2} & $\mathrm{~S}$ & $\mathrm{P}$ & \multicolumn{3}{|l|}{$\mathrm{O}$} \\
\hline & $\mathrm{N}$ & V & \multicolumn{3}{|l|}{$\mathrm{N}$} \\
\hline \multirow[t]{4}{*}{3} & $\mathrm{~S}$ & $\mathrm{P}$ & \multicolumn{3}{|l|}{ Pel } \\
\hline & $\mathrm{N}$ & V & \multicolumn{3}{|c|}{$\mathrm{N}$} \\
\hline & & & \multicolumn{3}{|c|}{ BIL } \\
\hline & & & \multicolumn{3}{|c|}{$\mathrm{V}$} \\
\hline \multirow[t]{4}{*}{4} & $\mathrm{~S}$ & $\mathrm{P}$ & \multicolumn{3}{|l|}{$\mathrm{K}$} \\
\hline & $\mathrm{N}$ & $\mathrm{N}$ & \multicolumn{3}{|l|}{$\mathrm{K}$} \\
\hline & & $\mathrm{V}$ & \multicolumn{3}{|c|}{ FD } \\
\hline & & BIL & & & \\
\hline \multirow[t]{2}{*}{5} & $\mathrm{~S}$ & $\mathrm{P}$ & $\mathrm{O}$ & K & \\
\hline & $\mathrm{N}$ & V & $\mathrm{N}$ & K & \\
\hline \multirow[t]{2}{*}{6} & S & $\mathrm{P}$ & $\mathrm{O} 1$ & 02 & \\
\hline & $\mathrm{N}$ & V & $\mathrm{N}$ & $\mathrm{N}$ & \\
\hline \multirow[t]{2}{*}{7} & S & $\mathrm{P}$ & O1 & $\mathrm{O} 2$ & K \\
\hline & $\mathrm{N}$ & V & $\mathrm{N}$ & $\mathrm{N}$ & KET \\
\hline
\end{tabular}

\section{Discussion}

From the structure data of the clause, phrase and clause patterns, then the hierarchy of grammar can be arranged as follows: 


\subsection{CFG}

Formally, a grammar consists of four elements:

1. T terminal finite set consisting of all symbols used to state the sentences in Indonesian language

!"\#\$ \%\&‘()*+,-./ $0123456789: ;<=>$ ?@ ABCDEFGHIJKLMNOPQRSTUVW

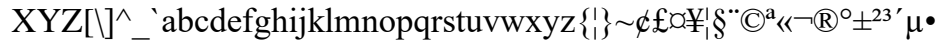

2. N Non-terminal finite set is a symbol to symbolize a sentence, phrase and word group. Table 3 consists of the list of the sentence symbol from the above clause structure, phrase and word group.

Table 3. Non Terminal (N)

\begin{tabular}{lll}
\hline No & \multicolumn{1}{c}{ Non Terminal } & Symbol \\
\hline 1 & Sentence/Kalimat & Kal \\
2 & Subjek & $\mathrm{S}$ \\
3 & Predicate & $\mathrm{P}$ \\
4 & Object & $\mathrm{O}$ \\
5 & Complement/Pelengkap & PEL \\
11 & Nomina & $\mathrm{N}$ \\
12 & Verb & $\mathrm{V}$ \\
13 & Adjective & Adj \\
14 & Adverb & Ket \\
15 & Number/Bilangan & BIL \\
16 & Question/Tanya & Tanya \\
17 & Conjunction & Hub \\
18 & Preposition/Kata Depan & Depan \\
19 & etc & \\
\hline
\end{tabular}

3. P Production Rule Finite Set. The production rule in this research is a combination of clause pattern and the phrase

Table 4. Production Rule

\begin{tabular}{|c|c|}
\hline No & $\begin{array}{l}\text { Production Rule } \\
\end{array}$ \\
\hline 1 & $\langle\mathrm{Kal}\rangle=\langle\mathrm{S}\rangle\langle\mathrm{P}\rangle$ \\
\hline 2 & $\langle\mathrm{Kal}\rangle=\langle\mathrm{S}\rangle\langle\mathrm{P}\rangle\langle\mathrm{O}\rangle$ \\
\hline 3 & $\langle\mathrm{Kal}\rangle=\langle\mathrm{S}\rangle\langle\mathrm{P}\rangle\langle\mathrm{PEL}\rangle$ \\
\hline 4 & $\langle\mathrm{Kal}\rangle=\langle\mathrm{S}\rangle\langle\mathrm{P}\rangle\langle\mathrm{O} 1\rangle\langle\mathrm{O} 2\rangle$ \\
\hline 5 & $\langle\mathrm{Kal}\rangle=\langle\mathrm{S}\rangle\langle\mathrm{P}\rangle\langle\mathrm{O}\rangle\langle\mathrm{K}\rangle$ \\
\hline 6 & $\langle\mathrm{Kal}\rangle=\langle\mathrm{S}\rangle\langle\mathrm{P}\rangle\langle\mathrm{PEL}\rangle\langle\mathrm{K}\rangle$ \\
\hline 7 & $\langle\mathrm{Kal}\rangle=\langle\mathrm{S}\rangle\langle\mathrm{P}\rangle\langle\mathrm{O} 1\rangle\langle\mathrm{O} 2\rangle\langle\mathrm{K}\rangle$ \\
\hline 8 & $\langle\mathrm{~S}\rangle=\langle\mathrm{N}\rangle$ \\
\hline 9 & $\langle\mathrm{P}\rangle=\langle\mathrm{N}\rangle|\langle\mathrm{V}\rangle|\langle$ Bil $\rangle \mid\langle$ Ket $\rangle$ \\
\hline 10 & $\langle\mathrm{O}\rangle=\langle\mathrm{N}\rangle$ \\
\hline 11 & $\langle\mathrm{~K}\rangle=\langle\mathrm{KET}\rangle$ \\
\hline 12 & $\langle\mathrm{PEL}\rangle=\langle\mathrm{N}\rangle \mid\langle\mathrm{BIL}\rangle$ \\
\hline 13 & $\langle\mathrm{~N}\rangle=\{$ aku, dia, saya, kamu, bakso... $\}$ \\
\hline 14 & $\langle\mathrm{~V}\rangle=\{$ makan, minum, pergi .... $\}$ \\
\hline 15 & $\langle$ Ket $\rangle=\{$ kemarin,$\ldots .\}$. \\
\hline 16 & $\langle$ Bil $\rangle=\{$ satu, dua ..... $\}$ \\
\hline
\end{tabular}

4. The $\mathrm{S} \varepsilon \mathrm{N}$ first symbol 
$<$ Kal $>$

\subsection{General Application on Application}

This application is a sentence pattern identification application in Indonesian language using Left-Corner Parsing.

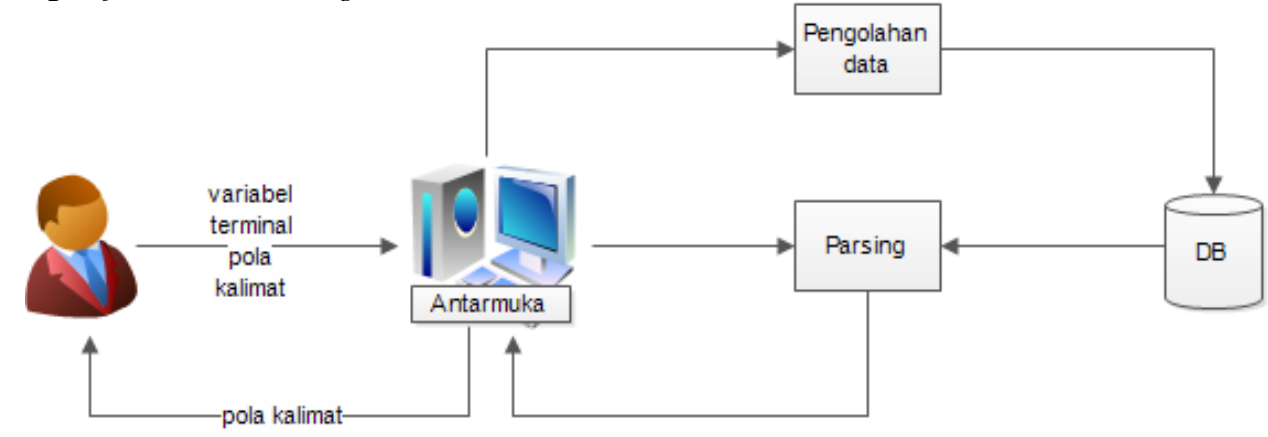

Fig. 5. Application Architecture

\section{The Needs on Application}

This application consists of four need module:

1. Variable Module: this module is used to process token variable data

2. Terminal Module: This module is used to manage the token terminal data

3. Pattern Module: This module is used to manage sentence pattern data

4. Parsing Module: This module is the main module used to process sentence pattern identification parsing

\subsection{Application Description Model}

Application description model includes the data model and process specification

\section{Data Model}

Table of Variable. This is used to store the variable data

Table 5. Variable Table Structure

\begin{tabular}{|c|l|l|l|}
\hline \multicolumn{1}{|c|}{ Field } & Type & Comment \\
\hline 9 & id_variabel & int (11) & \\
& NOT NULL & \\
variabel & varchar(35) \\
NULL
\end{tabular}

Table of Terminal. This is used to store the terminal data

Table 6 : Terminal Table Structure

\begin{tabular}{|l|l|l|}
\hline Field & Type & Comment \\
\hline 7 id_terminal & int (11) & NOT NULL \\
\hline 7 id_variabel & int(11) & NOT NULL \\
\hline \multirow{2}{*}{ terminal } & varchar(35) \\
& NULL & \\
\hline
\end{tabular}


Table of Pattern. This is used to store the pattern data.

Table 7. Pattern Table Structure

\begin{tabular}{|c|c|c|c|}
\hline & Field & Type & Comment \\
\hline ? & id_pola & $\begin{array}{l}\text { int (11) } \\
\text { NOT NULL }\end{array}$ & \\
\hline จ & id_variabel & $\begin{array}{l}\text { int (11) } \\
\text { NOT NULL }\end{array}$ & \\
\hline 8 & id_hasil & $\begin{array}{l}\text { int (11) } \\
\text { NOT NULL }\end{array}$ & \\
\hline
\end{tabular}

\section{Table of Relation}

The relation among the tables is shown in the following picture.
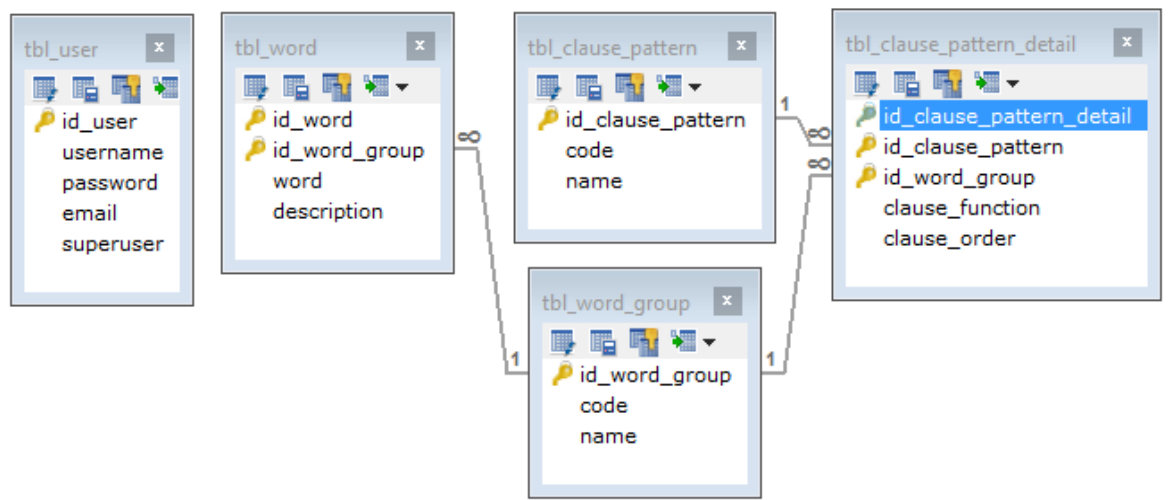

Fig. 6. Table of Relation

The data managed includes:

1. Words, a list of Indonesian vocabulary

2. Part of speech is part of speech of each word.

3. Clause Pattern is sentence patter structure as stated in CFG in Table 4. The samples of the data are SP, SPO, SPK, SPPel, etc.

4. Detail of Clause Pattern, is the detail of clause pattern previously stated. The sample of SP pattern can be formed by some combinations of part of speech. From the table 4, it can be formed sentences with some series combinations of part of speech, which are:

5. $\langle$ Kal $\rangle \quad \rightarrow\langle\mathrm{S}\rangle\langle\mathrm{P}\rangle$

$\langle\mathrm{S}\rangle \quad \rightarrow\langle\mathrm{N}\rangle$

$\langle\mathrm{P}\rangle \quad \rightarrow\langle\mathrm{N}\rangle|\langle\mathrm{V}\rangle|\langle$ Bil $\rangle \mid\langle$ Ket $\rangle$

$\langle\mathrm{Kal}\rangle \quad \rightarrow\langle\mathrm{N}\rangle\langle\mathrm{N}\rangle * \mathrm{SP} 1$

$\langle\mathrm{Kal}\rangle \quad \rightarrow\langle\mathrm{N}\rangle\langle\mathrm{V}\rangle * \mathrm{SP} 2$

$<\mathrm{Kal}\rangle \quad \rightarrow\langle\mathrm{N}\rangle\langle\mathrm{Bil}\rangle * \mathrm{SP} 3$

$<$ Kal $>\quad \rightarrow\langle\mathrm{N}\rangle\langle$ Ket $>* \mathrm{SP} 4$

SP1, SP2, SP3 and SP4 are some clause patterns which can be produced for SP clause pattern. On the SP1, a sentence consisting of two words with the first word is $\mathrm{N}$ and the second is also N. Next, a table of clause pattern detail is formed which consists of clause pattern id, part of speech id, clause function id, and its appearance sequence in the clause pattern. 
Process Specification. The flow of how function run in the application shown in flowchart in the following figure 7

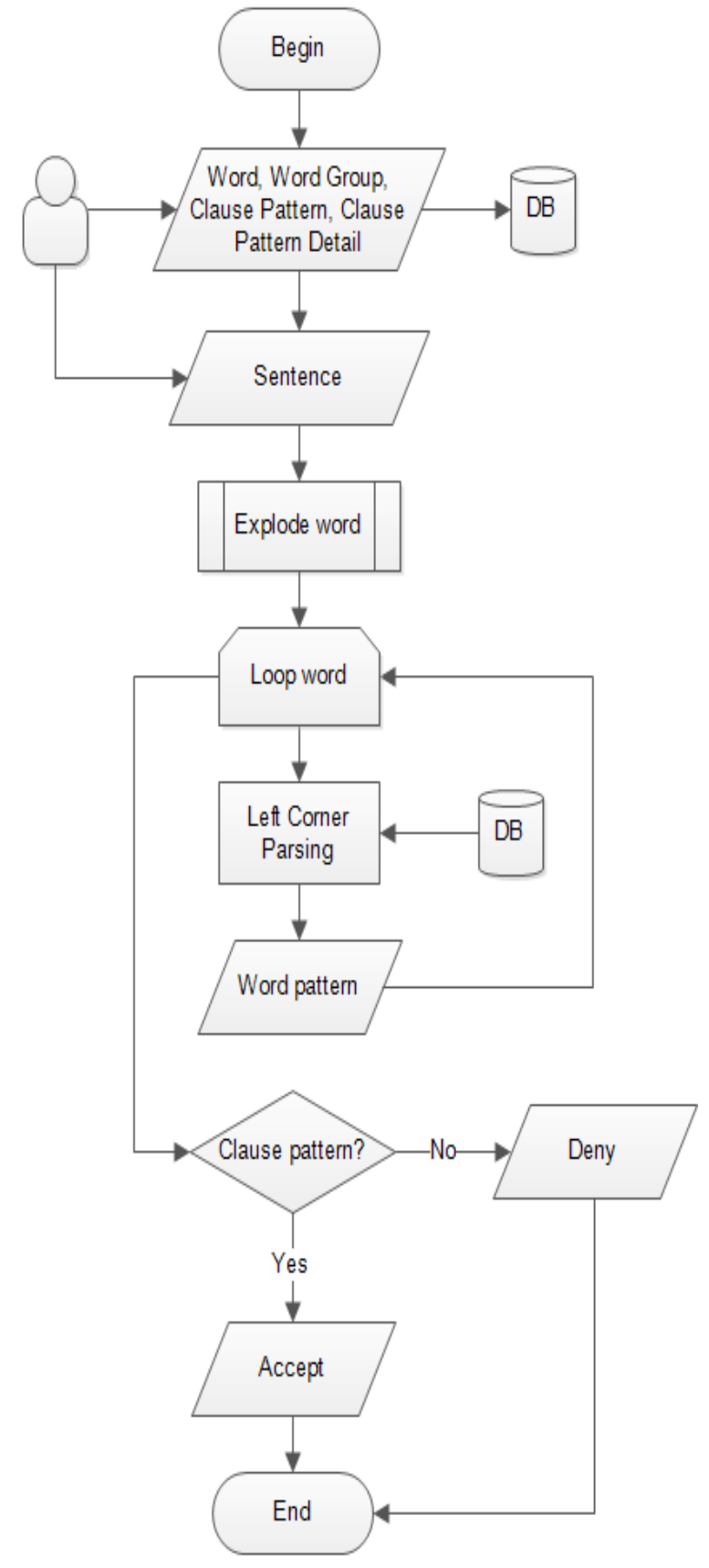

Fig 7. Flowchart 
Pseudo Code Left Corner Parsing. The following pseudo code explains the logic of how the application runs.

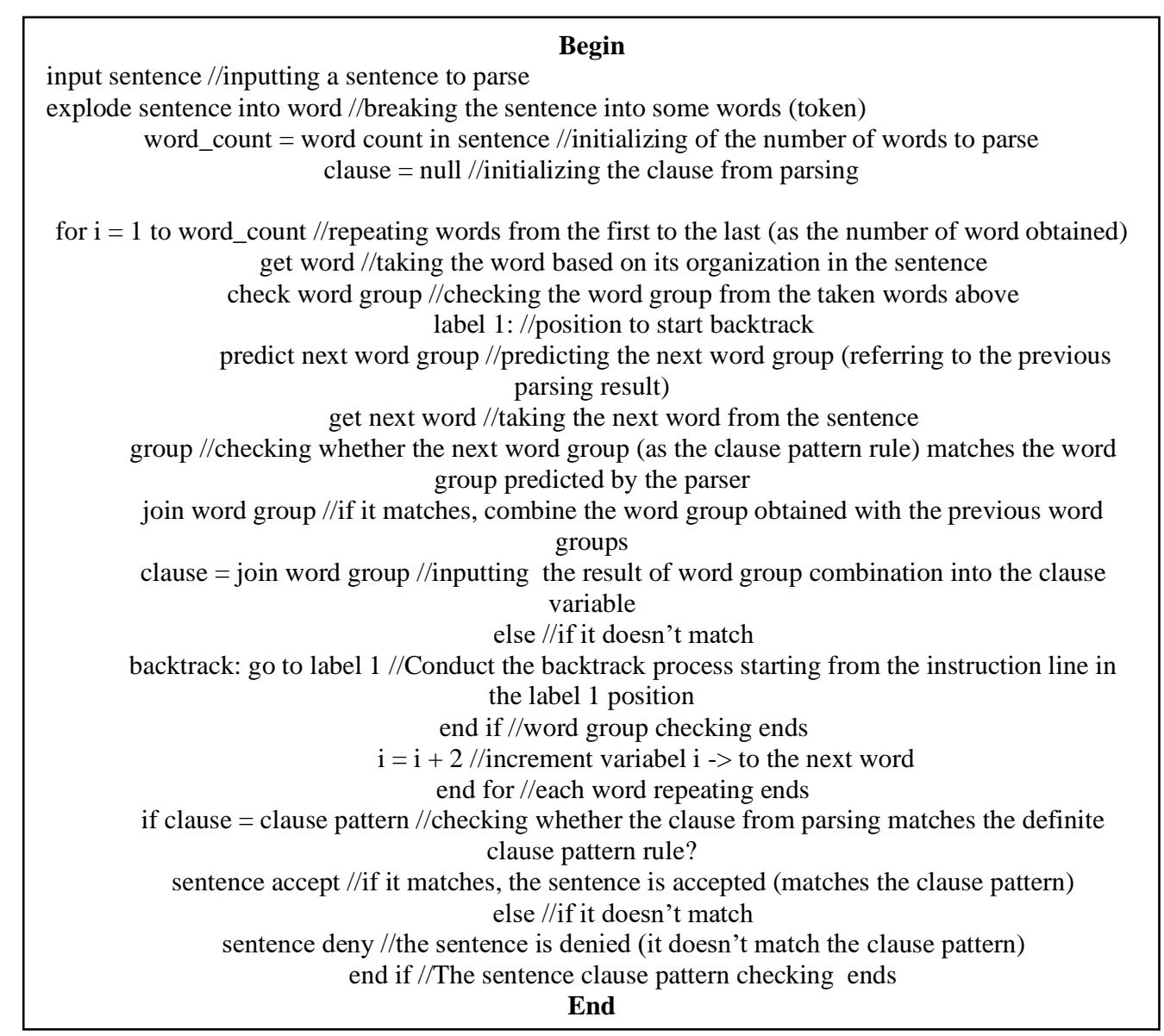

Fig. 8. Pseudo Code Left Corner Parsing

Program Implementation.The following figure 9 shows the application display for the sentence based on the rule stored. 


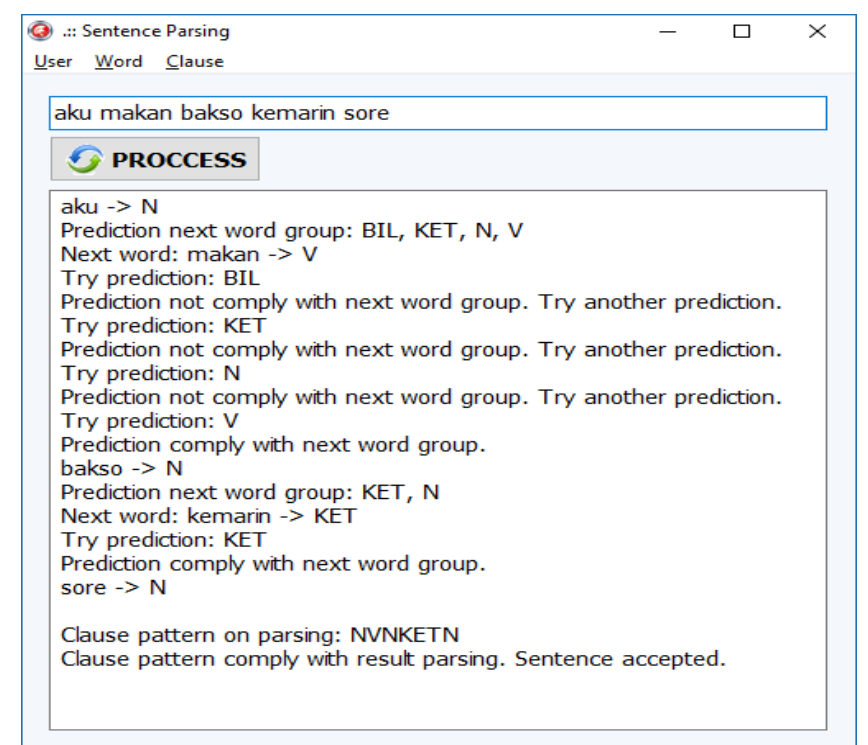

Fig. 9. Application Display for the sentence which matches the clause

Figure 10 shows the manual process of left corner parsing based on stored rules for the sentence which matches the clause.

Figure 11 shows the application display for the sentence which does not match the clause.

Figure 12 shows the manual process of left corner parsing based on stored rules for the sentence does not matches the clause. 

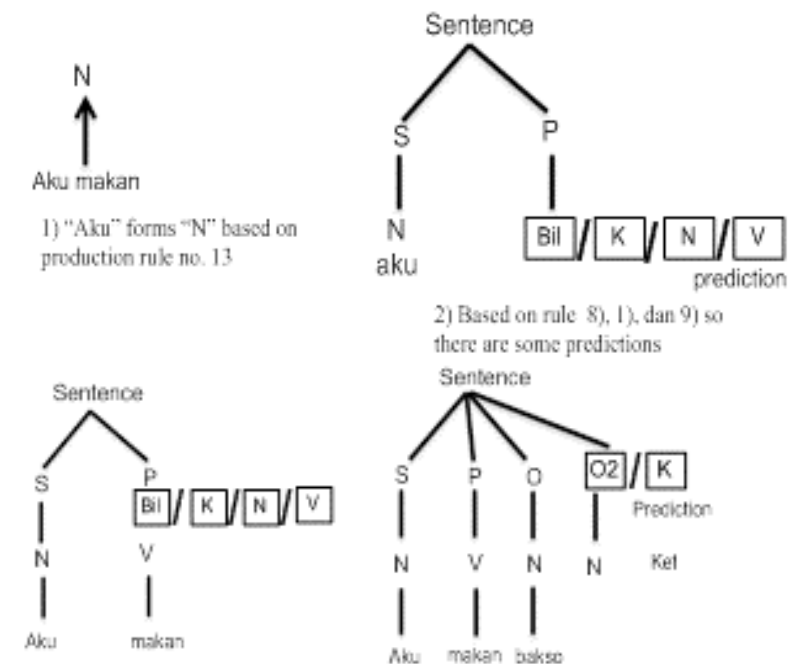

1) "makan" 6ums "V" bestd as ruke

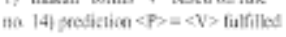

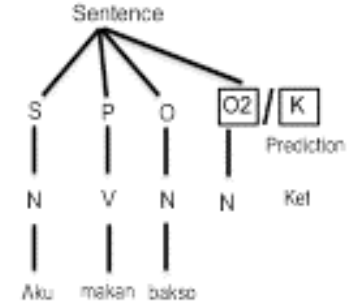

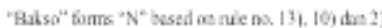

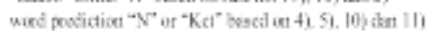

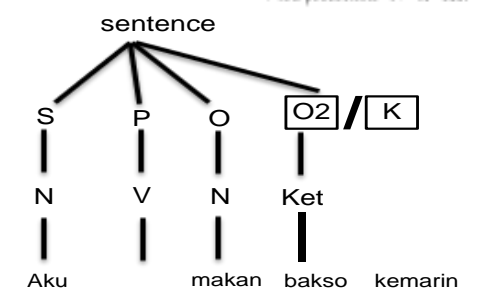

4) "kemarin" forms "ket" based on rule no 15)
Prediction $K=<$ Ket $>$ Is fulfilled based on rule no 11)

Prediction $\mathrm{K}=\langle$ Ket $>$ Is fulfilled based on rule no 11)
words are completely inputted and the pattern produced is $\mathrm{N}$
$\mathrm{V} N$ Ket It matches the stored rule

Fig. 10. Manual Process of Left Corner Parsing for the sentence which matches the clause

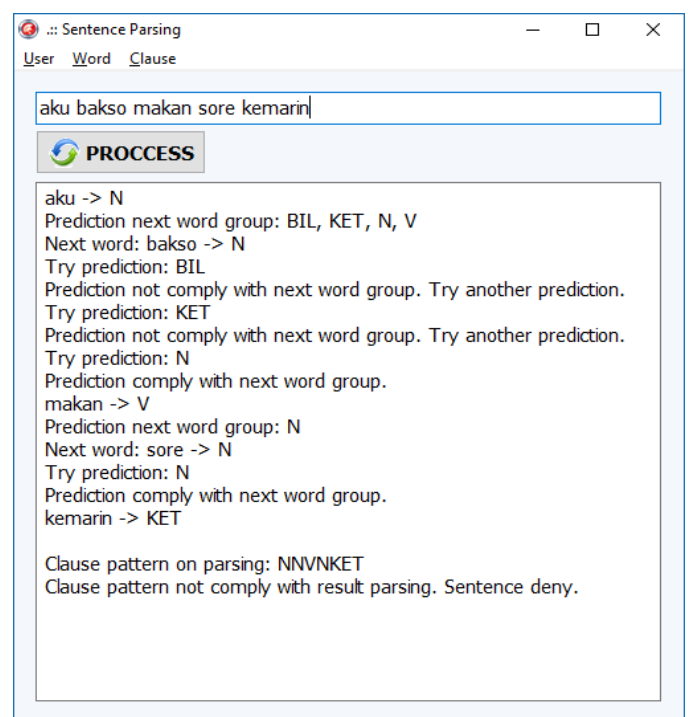

Fig. 11. Application Display for the sentence which does not match the clause 

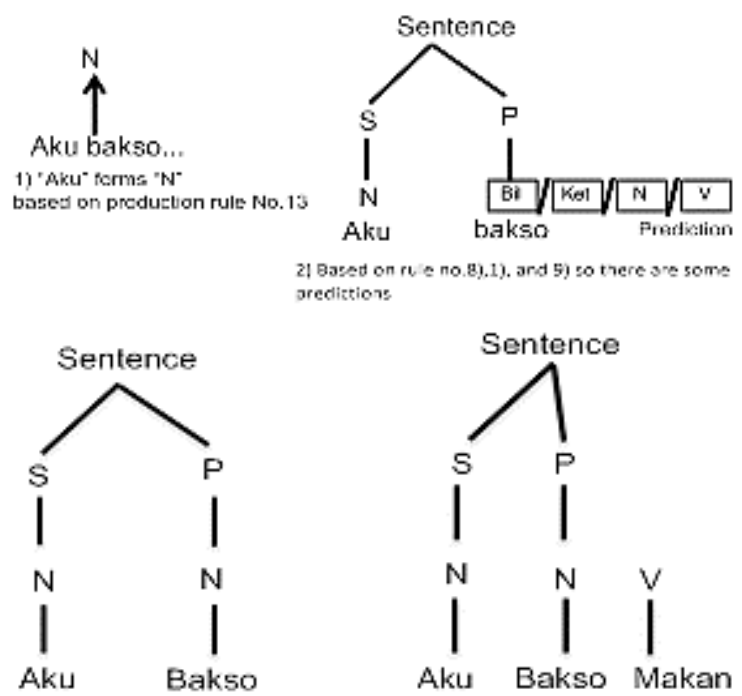

3) "bakso" forms "N" based on rule ro. 14

4) "makan" forms $Y$ predictian is fulfilled

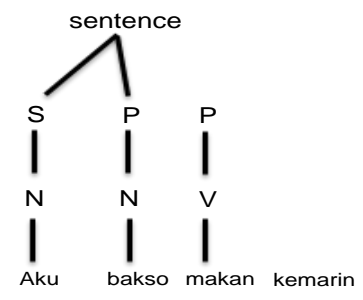

5) Based on rule no.9) The pettern formed is Kal $->\langle\mathrm{S}\rangle\langle\mathrm{P}\rangle\langle\mathrm{P}\rangle$. It doesn't match the rule The sentence

Fig. 12. Manual Process of Left Corner Parsing for the sentence which matches the clause

\section{Conclusion \& Suggestion}

\subsection{Conclusion}

1. Left corner parsing can be implemented in sentence of Indonesian language.

2. The first word influences the derivation of the next sentence.

3. The number of production rules affect many types of patterns are recognized.

\subsection{Suggestion}

1. It can be developed for other language parsing by matching the pattern of the language clause. 
2. It can be developed rules of parsing the broader pattern of clauses such as those involving the phrase

Acknowledgement. The author would like to thank the Kemenristekdikti Indonesia which has provided research funding through research grants Penelitian Dosen Pemula 2015.

\section{References}

[1] B. Patrut, "Syntactic Analytic Based on Morphological Characteristic Features of the Romanian Language." .

[2] M. Abdurrohman, S. Hadi, and D. Rohidin, "Grammar Checking in English language Using Left Corner Parsing Algorithm," in Proceeding of National Scientific Seminar on Computer and Intelligent system (KOMMIT2006).

[3] D. J. and J. H. Martin, Speech and Language Processing, An Introduction to Natural Language Processing, Computational Linguistic and Speech Recognition. Prentice Hall Series In Artificial Intelligence, 1999

[4] Puslit.petra.ac.id, "James Suciadi, Analysis Study on Parsing Method and Semantic Interpretation on Natural Language Processing,." [Online]. Available: http://puslit.petra.ac.id/journals/informatics.

[5] D. W. Patterson, Introduction to Artificial Intelligence and Expert System. Prentice Hall International, Inc, 1990

[6] S. . Tjiptadi, Bambang, Drs., Negoro, Summary of Indonesian language Grammar,. Yudhistira, 1983.

[7] Ramlan, Part of Speech. Yogyakarta: Andi Offset, 1985. 